University of Nebraska - Lincoln

DigitalCommons@University of Nebraska - Lincoln

\title{
Experimental and modeled thermoregulatory costs of repeated sublethal oil exposure in the Double-crested Cormorant, Phalacrocorax auritus
}

\author{
Paul D. Mathewson \\ University of Wisconsin-Madison, mathewson@wisc.edu \\ Katie C. Hanson-Dorr \\ USDA National Wildlife Research Center \\ Warren P. Porter \\ University of Wisconsin-Madison \\ Steven J. Bursian \\ Michigan State University \\ Karen M. Dean \\ Abt Associates
}

See next page for additional authors

Follow this and additional works at: https://digitalcommons.unl.edu/icwdm_usdanwrc

Part of the Life Sciences Commons

Mathewson, Paul D.; Hanson-Dorr, Katie C.; Porter, Warren P.; Bursian, Steven J.; Dean, Karen M.; Healy, Kate; Horak, Katherine; Link, Jane E.; Harr, K. E.; and Dorr, Brain S., "Experimental and modeled thermoregulatory costs of repeated sublethal oil exposure in the Double-crested Cormorant, Phalacrocorax auritus" (2018). USDA National Wildlife Research Center - Staff Publications. 2146.

https://digitalcommons.unl.edu/icwdm_usdanwrc/2146

This Article is brought to you for free and open access by the U.S. Department of Agriculture: Animal and Plant Health Inspection Service at DigitalCommons@University of Nebraska - Lincoln. It has been accepted for inclusion in USDA National Wildlife Research Center - Staff Publications by an authorized administrator of DigitalCommons@University of Nebraska - Lincoln. 


\section{Authors}

Paul D. Mathewson, Katie C. Hanson-Dorr, Warren P. Porter, Steven J. Bursian, Karen M. Dean, Kate Healy, Katherine Horak, Jane E. Link, K. E. Harr, and Brain S. Dorr 


\title{
Experimental and modeled thermoregulatory costs of repeated sublethal oil exposure in the Double-crested Cormorant, Phalacrocorax auritus
}

\author{
Paul D. Mathewson ${ }^{\mathrm{a}, *}$, Katie C. Hanson-Dorr ${ }^{\mathrm{b}}$, Warren P. Porter ${ }^{\mathrm{a}}$, Steven J. Bursian ${ }^{\mathrm{c}}$, \\ Karen M. Dean ${ }^{\mathrm{d}}$, Kate Healy ${ }^{\mathrm{e}}$, Katherine $\operatorname{Horak}^{\mathrm{f}}$, Jane E. Link ${ }^{\mathrm{c}}$, K.E. Harr ${ }^{\mathrm{g}}$, Brian S. Dorr ${ }^{\mathrm{b}}$ \\ a Department of Integrative Biology, University of Wisconsin-Madison, 250 North Mills Street, Madison, WI 53706, USA \\ ${ }^{\mathrm{b}}$ U.S. Department of Agriculture, Wildlife Services, National Wildlife Research Center, P.O. Box 6099, Mississippi State, MS 39762, USA \\ ${ }^{\mathrm{c}}$ Department of Animal Science, Michigan State University, 474 South Shaw Lane, East Lansing, MI 48824, USA \\ d Abt Associates, 1881 Ninth St., Ste. 201, Boulder, CO 80302-5148, USA \\ e U.S. Fish and Wildlife Service, Natural Resource Damage Assessment Regional Field Office, 341 Greeno Road North, Suite A, Fairhope, AL 36532, USA \\ ${ }^{\mathrm{f}}$ U.S. Department of Agriculture, Wildlife Services, National Wildlife Research, Fort Collins, CO 80521, USA \\ g URIKA, LLC., Mukilteo, WA, USA
}

\section{A R T I C L E I N F O}

\section{Keywords:}

Bioenergetics model

Cormorant

Marine oil pollution

Niche Mapper

Seabirds

Thermoregulation

\begin{abstract}
A B S T R A C T
To fully understand the impact of oil exposure, it is important to understand sublethal effects like how increased thermoregulatory costs may affect survival and reproduction. However, it is difficult and time-consuming to measure these effects in wild animals. We present a novel use of a bioenergetics model, Niche Mapper ${ }^{\mathrm{TM}}$, to estimate thermoregulatory impacts of oiling, using data from captive Double-crested Cormorants (Phalacrocorax auritus) experimentally exposed to oil. Oiled cormorants had significant increases in surface body temperatures following exposure. Niche Mapper accurately predicted surface temperatures and metabolic rates for unoiled and oiled cormorants and predicted $13-18 \%$ increased daily energetic demands due to increased thermoregulatory costs of oiling, consistent with increased food consumption observed in experimentally oiled cormorants. We show that Niche Mapper can provide valuable insight into sublethal oiling effects by quantifying the extent to which thermoregulatory costs divert energy resources away from important life processes like maintenance, reproduction and migration.
\end{abstract}

\section{Introduction}

The threat of oil pollution to marine birds is well-documented (e.g., Votier et al., 2005), and can affect marine birds indirectly (e.g., killing or contaminating food sources) or directly. The direct effects of oil exposure stem from the toxicity of ingested oil and adverse effects of plumage oiling, the latter being the focus of this work. Oil exposure compromises the integrity of a bird's feather microstructure by collapsing the interlocking structure of feather elements. This results in feathers matting together, causing the insulative air layer in the plumage to be displaced and a loss of waterproofing (O'Hara and Morandin, 2010). This, in turn, affects the thermal balance of oil-exposed birds that can require additional energetic expenditures to maintain homeothermy.

Experimental studies have documented increased metabolic heat production in response to oiling in several avian species (Table S1). The magnitude of increased heat production is dependent on dosage, environmental temperature, exposure to water, and differences in plumage types among species. At one extreme, heavily oiled birds in cold aquatic environments can die of hypothermia or starvation if unable to feed enough to offset increased energetic requirements (e.g., Oka and Okuyama, 2000). For birds in milder environments or that are less-heavily oiled, the increased energy expenditures following oiling may not be lethal but may still affect fitness by diverting resources away from maintenance, growth, and reproduction.

While large, catastrophic spills that cause immediate mass mortalities garner much of the media and scientific attention, there is growing recognition of the need to better understand the effect of exposure to chronic (low volume) oil discharges (Wiese and Robertson, 2004; Henkel et al., 2014; Fraser and Racine, 2016). A majority of anthropogenic oil pollution comes from chronic discharges from sources like the offshore oil and gas industry, shipping vessels and nonpoint runoff from land-based activities (O'Hara and Morandin, 2010; Henkel et al., 2014). Chronic exposure can cause mortality in some

\footnotetext{
* Corresponding author.

E-mail address: mathewson@wisc.edu (P.D. Mathewson).
} 
locations (e.g., Wiese and Ryan, 2003), but there are also likely more widespread sublethal effects of such exposures.

To date we are unaware of attempts to model repeated sublethal oil exposure and predict the effects due to increased thermoregulatory costs. Here we present a novel use of a bioenergetics model, Niche Mapper $^{\mathrm{TM}}$, to predict the thermoregulatory effect of oil exposure on the Double-crested Cormorant (Phalacrocorax auritus; hereafter cormorant), a large, diving waterbird often impacted by oil spills (Dorr et al., 2015). We develop an "oiled' cormorant model by modifying the inputs used by Niche Mapper to calculate body insulation to simulate oil introduced into the plumage. We then test Niche Mapper's ability to accurately model thermoregulation in oiled and unoiled cormorants by comparing predicted surface temperatures and energy expenditures to those measured in captive cormorants experimentally exposed to oil. Mechanistically modeling the thermoregulatory effects of oil exposure allows for simulations of wild animals' energetics to gain a more complete understanding of the effects of oil pollution on wildlife.

\section{Methods}

\subsection{Summary of live cormorant experiments}

As part of the Natural Resource Damage Assessment performed in response to the 2010 Deepwater Horizon (DWH) oil spill in the Gulf of Mexico, wild cormorants were captured from Mississippi and Alabama, USA, and transported to captive facilities at the National Wildlife Research Center, Mississippi Field Station (Bursian et al., 2017). The focus of the present work is developing modeling techniques and so we summarize the live bird experiments to provide context. For a detailed description of procedures see Cunningham et al. (2017).

All cormorants were individually housed in $1.5 \times 1.5 \times 1.8 \mathrm{~m}$ cages containing 190-liter plastic water tanks that were refilled daily. Cormorants were offered $600 \mathrm{~g}$ of live channel catfish (Ictalurus punctatus) daily. All birds had an Advanced Telemetry Systems (ATS, Isanti, MN USA) F1815T very high frequency temperature transmitter surgically implanted in the coelom prior to study initiation to monitor internal body temperature daily (see Scherr, 2009 for details). Cormorants were allowed to acclimate to captivity and recover from surgery for a minimum of 21 days prior to initiation of the oiling study.

Twenty-five cormorants were assigned to control $(n=12)$ or oiled $(n=13)$ treatment groups. Seven cormorants had evidence of preexisting illness based on monocyte counts and were assigned randomly between the control and oiled groups ( 4 and 3 birds respectively). During the course of the trial, one bird from the control group (day 1) and two birds from the oiled group (day 15 and 19) died (Cunningham et al., 2017).

Cormorants in the oiled group were exposed to artificially weathered DWH oil by applying approximately $6.5 \mathrm{~g}$ of oil to both the breast and back by brush. The oil was applied across an area accounting for $20 \%$ of the total body surface area excluding wings and tail; subsequent preening by the birds further spread the oil. Cormorants in the control group received the same treatment except that oil was replaced with water. Oil or water was applied to the birds every three days through day 16 of the trial (Table S2). Body weight was measured every three days for the duration of the trial and at necropsy.

External body temperature of all cormorants was taken with a handheld scanning thermograph camera (FLIR ${ }^{\circledast}$ ) three days prior to day 1 oiling, and every six days thereafter (Table S2). Birds were taken from their cage to an adjacent room where they were held at a standard distance and position for each photo to ensure reproducibility. Temperatures for different body parts were extracted using FLIR ${ }^{\circledast}$ ThermaCAM 342 Researcher Pro 2.7 software. Food intake was calculated based on daily consumption of fish. Visual bird health checks were conducted twice daily (Cunningham et al., 2017).

\subsection{Niche Mapper description}

Niche Mapper (Porter and Mitchell, 2006) is a bioenergetics model that has been previously shown to accurately predict energetic requirements as a function of environmental conditions and animal morphological and physiological properties for a wide variety of animals, including several waterbirds: cormorants (Phalacrocorax sp.), Brünnich's guillemots (Ura lomvia), and little auks (Alle alle) (Fort et al., 2009, 2011; Göktepe et al., 2012). Niche Mapper consists of two submodels: a microclimate model and an animal model. The microclimate model uses macroclimate data (maximum and minimum daily air temperatures, cloud cover, wind speed, relative humidity), substrate properties, geographic location, and time of year to calculate hourly environmental conditions at the animal's height (see Fuentes and Porter, 2013 for details).

The animal model then uses the hourly outputs from the microclimate model and animal properties to iteratively solve a heat balance equation to find the metabolic rate needed for the animal to maintain its body temperature, accounting for convective, radiative, evaporative, conductive and solar heat fluxes with its microenvironment (see Supplemental materials and Mathewson and Porter, 2013 for details). Most relevant to this work, Niche Mapper calculates animal surface temperatures based on core temperature, physical dimensions, and insulation of the body part in order to compute heat flux with the environment. Thus, the model allows us to explore how altered insulation (e.g., in response to oiling) affects surface temperatures and, ultimately, heat loss to the environment.

We updated the cormorant model used by Göktepe et al. (2012) to a multipart model with truncated cones for the beak and head, cylinders for the neck and legs, and an ellipsoid for the torso (Fig. S1). During diurnal and crepuscular hours, all body parts were exposed to the environment. During nocturnal hours, we assumed no heat loss for the head (tucked under wings) and $30 \%$ of the neck (in contact with torso) to simulate birds in a sleeping posture. Key animal model inputs are summarized in Table 1, and the following physiological thermoregulatory options were allowed: vasodilation and vasoconstriction, increasing body temperature, ptiloerection, and gular fluttering. Leg and beak body temperatures were allowed to drop below body temperatures for other body parts to simulate counter-current exchange mechanisms (Fitzpatrick et al., 2015). See Supporting information for additional information on Niche Mapper operation.

\subsection{Niche Mapper metabolic chamber simulations}

We first evaluated the unoiled cormorant model with a metabolic chamber simulation to compare predicted metabolic rates as a function of air temperature to those reported by Enstipp et al. (2006, 2008). In this simulation, all environmental temperatures (air, ground, and sky) were set to the same value and increased incrementally. We assumed no solar radiation, $5 \%$ relative humidity, and wind speeds of 0.1 or $1.0 \mathrm{~m} / \mathrm{s}$ to account for uncertainty regarding the velocity of the airflow in the experimental metabolic chambers.

We also compared Niche Mapper heat production predictions for cormorants resting on the water surface to those measured by Enstipp et al. (2006) in a metabolic chamber. We simulated cormorants as having their legs fully submerged and $50-90 \%$ of their torso submerged. Double-crested Cormorant plumage is partially wettable (Mahoney, 1984). Based on studies by Enstipp et al. (2006) and Grémillet et al. $(1998,2005)$ on shallowly-submerged Double-crested Cormorant and Great Cormorant (Phalacrocorax carbo) carcasses respectively, we assumed water penetration reduced the effective 'dry' insulation layer thickness in the model to $2 \mathrm{~mm}$.

\subsection{Surface temperature comparisons}

For each day that FLIR images were taken of the live cormorants, we 
Table 1

Key cormorant model inputs for Niche Mapper.

\begin{tabular}{|c|c|c|}
\hline Parameter & Value & Source \\
\hline Body temperature $\left({ }^{\circ} \mathrm{C}\right)$ & $40-43$ & Enstipp et al. (2006, 2008); this study. \\
\hline Resting metabolic rate $(\mathrm{W} / \mathrm{kg})$ & 4.59 & Enstipp et al. (2006) \\
\hline Plumage depth: head (dorsal/ventral; mm) & $2.8 / 2.8$ & This study; measured on a male specimen from the UW Madison Zoology Museum \\
\hline Plumage depth: neck (dorsal/ventral; mm) & $4.5 / 4.5$ & This study; measured on a male specimen from the UW Madison Zoology Museum \\
\hline Plumage depth: torso (dorsal/ventral; mm) & $4.5 / 14$ & This study; measured on a male specimen from the UW Madison Zoology Museum \\
\hline Plumage reflectivity (dorsal/ventral) & $0.134 / 0.155$ & Göktepe et al. (2012) \\
\hline Plumage element diameter (um) & 25 & Göktepe et al. (2012) \\
\hline Plumage element density $\left(\#\right.$ per $\mathrm{cm}^{2}$ ) & 14,400 & Göktepe et al. (2012) \\
\hline Flesh thermal conductivity (dorsal/ventral; $\mathrm{W} / \mathrm{mC}$ ) & $0.4-2.8$ & Cho (1969) \\
\hline Oxygen extraction efficiency (\%) & 34 & Göktepe et al. (2012) \\
\hline Digestive efficiency (\%) & 79 & Brugger (1993) \\
\hline Food \% dry matter & 22 & USDA (2016; report for raw, farmed, channel catfish) \\
\hline Food dry matter $\%$ protein & 65 & USDA (2016), correcting for bones accounting for $14 \%$ of weight (Martin et al., 2000) \\
\hline Food dry matter $\%$ fat & 25 & USDA (2016), correcting for bones accounting for $14 \%$ of weight (Martin et al., 2000) \\
\hline Food dry matter \% carbohydrates & 0.0 & USDA (2016) \\
\hline
\end{tabular}

simulated model birds in a room with the same temperature and relative humidity as the photograph room, assuming negligible wind $(0.1 \mathrm{~m} / \mathrm{s})$, no solar input, and that ceiling and floor temperatures were the same as air temperature (Table S2). We also simulated the model cormorants in the temperature of the animal room as the photographs were taken within minutes of the birds being taken into the photograph room, and the birds may not have reached a new thermal steady state assumed by Niche Mapper. Observed surface temperatures were expected to be between those predicted for birds simulated in the photograph and animal rooms. The mass and body temperature of the model bird was set to the average mass and body temperature of all unoiled birds at the time of the photograph, and we used a target resting metabolic rate of $4.59 \mathrm{~W} / \mathrm{kg}$ (Enstipp et al., 2006). Surface temperatures predicted by Niche Mapper were then compared to temperatures extracted from the FLIR images of experimentally oiled birds.

\subsection{Simulating oil exposure}

To simulate oil exposure, we modified plumage layer inputs from the unoiled model. In the unoiled model, feather layer thermal conductivity is calculated using the thermal conductivities of air and keratin in relative proportion of the two materials in the layer. To simulate introduction of oil, we added the thermal conductivity of crude oil $(0.135 \mathrm{~W} / \mathrm{mC}$; Elam et al., 1989) to the feather layer thermal conductivity calculation, partially or completely replacing the contribution of air. We also reduced feather layer depths, feather density, and ptiloerection abilities based on observations of feather matting and feather plucking in live oiled birds (Cunningham et al., 2017).

The first FLIR images of the oiled birds were taken before any oiling, and the surface temperature comparisons were made using the unoiled cormorant model as described above. Subsequent FLIR images were taken after one, three, five, and six oil applications. Surface temperature differences between oiled and control birds were similar between oil applications five and six. We thus developed models for three stages of oiling: one application (Stage 1), three applications (Stage 2), and five/six applications (Stage 3). For each oil-exposure model, the feather layer input changes were manipulated to reflect observed physical changes in the plumage (Cunningham et al., 2017) until the resulting surface temperature calculations were similar to the observed surface temperatures (Table 2).

Metabolic chamber simulations (as described earlier for the unoiled model), were performed for each of the model oiling stages to compare predicted effects to effects on live birds reported in the literature. For cormorants simulated in water we assumed a range of additional water penetration due to oil exposure, from no additional penetration $(2 \mathrm{~mm}$ insulating layer retained) to full penetration (skin in contact with water), to bound uncertainty in the true effect.

\subsection{Feeding experiment simulation}

To compare Niche Mapper predictions for daily energetic expenditure to observed energetic expenditure (using food consumption as a proxy) in the live cormorants, we simulated individual cormorants in their holding pens over the course of the experiment. The microclimate submodel used daily maximum and minimum air temperatures recorded in the animal room to calculate daily ambient temperature profiles, assuming minimum temperatures occurred $1 \mathrm{~h}$ prior to sunrise and maximum temperatures occurred $1 \mathrm{~h}$ after solar noon. We assumed no solar input, negligible wind $(0.1 \mathrm{~m} / \mathrm{s})$, and floor and ceiling temperatures being equal to air temperature.

Birds were observed to spend most of the day resting or preening, except for about $2 \mathrm{~h}$ of swimming per day to forage for fish. Thus, we assumed an activity multiplier of $1.75 \times$ resting metabolic rate (RMR) for each hour to simulate resting and preening activities during diurnal

Table 2

Modifications to model cormorant plumage inputs used to simulate oil exposure.

\begin{tabular}{|c|c|c|c|}
\hline Body part & Oil stage 1 (one oil application) & Oil stage 2 (three oil applications) & Oil stage 3 (five/six oil applications) \\
\hline Head & No effect & $\begin{array}{l}\text { Plumage depth decreased } 0.5 \mathrm{~mm} \text {; Non-feathered portion } \\
\text { of plumage matrix modeled as oil (25\%) and air (75\%); } \\
\text { ability to ptiloerect reduced } 13 \% \text {. }\end{array}$ & $\begin{array}{l}\text { Plumage depth decreased } 0.5 \mathrm{~mm} \text {; non-feathered portion of } \\
\text { plumage matrix modeled as oil (25\%) and air ( } 75 \% \text {; ability to } \\
\text { ptiloerect reduced } 13 \% \text {. }\end{array}$ \\
\hline Neck & No effect & $\begin{array}{l}\text { Plumage depth decreased } 0.5 \mathrm{~mm} \text {; non-feathered portion } \\
\text { of plumage matrix modeled as oil (25\%) and air (75\%); } \\
\text { ability to ptiloerect reduced } 13 \% \text {. }\end{array}$ & $\begin{array}{l}\text { Plumage depth decreased } 0.5 \mathrm{~mm} \text {; non-feathered portion of } \\
\text { plumage matrix modeled as oil (25\%) and air (75\%); ability to } \\
\text { ptiloerect reduced } 13 \% \text {. }\end{array}$ \\
\hline Breast & $\begin{array}{l}\text { Non-feathered portion of plumage } \\
\text { matrix modeled as oil (10\%) and air } \\
(90 \%)\end{array}$ & $\begin{array}{l}\text { Plumage depth decreased } 2 \mathrm{~mm} \text {; non-feathered portion of } \\
\text { plumage matrix modeled as oil (10\%) and air (90\%); } \\
\text { ability to ptiloerect reduced } 63 \% \text {. }\end{array}$ & $\begin{array}{l}\text { Plumage depth decreased } 3 \mathrm{~mm} \text {; non-feathered portion of } \\
\text { plumage matrix modeled as oil (50\%) and air (50\%) ability to } \\
\text { ptiloerect reduced } 63 \% \text {. }\end{array}$ \\
\hline Back & $\begin{array}{l}\text { Non-feathered portion of plumage } \\
\text { matrix modeled as oil }\end{array}$ & $\begin{array}{l}\text { Plumage depth decreased } 2 \mathrm{~mm} \text {; non-feathered portion of } \\
\text { plumage matrix modeled as oil; ability to ptiloerect } \\
\text { reduced } 63 \% \text {. }\end{array}$ & $\begin{array}{l}\text { Plumage depth decreased } 3 \mathrm{~mm} \text {; non-feathered portion of } \\
\text { plumage matrix modeled as oil; ability to ptiloerect reduced } 63 \% \text {; } \\
\text { feather density reduced to } 5000 \text { elements } / \mathrm{cm}^{2} \text {. }\end{array}$ \\
\hline
\end{tabular}


and crepuscular hours (see Goldstein, 1988 reporting preening activity multipliers of 1.3-2.5 for a variety of species). The water temperature was assumed to be the average of the daily maximum and minimum air temperature. Based on observations, the birds were simulated to spend $10 \%$ of their time in the tanks diving for fish using an activity multiplier of $5 \times$ RMR (Enstipp et al., 2006) and the rest of the time floating on the water surface with legs and $70 \%$ of the torso submerged. For nocturnal hours, we assumed no activity multipliers.

Body mass of the model birds was assumed to change linearly between the days when measurements were made. Oiled group individuals were modeled using the same model as the control birds for days prior to the first oiling. Transitions to oil stages 2 and 3 were assumed to occur following the oil application in between the days when FLIR images were taken (Table S2).

\subsection{Statistical analyses}

To test the effect of treatment on observed surface temperatures we constructed linear models of surface temperature as a function of treatment group for each body part for each photograph day in $\mathrm{R}$ version 3.4.0 (R Core Team, 2017). Significance of treatment group was evaluated using an F-test. To test the effect of treatment on observed internal body temperature and food consumption we performed linear mixed effects analyses using the lme4 package (Bates et al., 2015) in R. Fixed effects were experiment day and treatment class (oiled or unoiled), with interaction allowed between the effects. Individual bird identifiers were included as a random effect, using both random intercepts and slopes (with experiment day as a covariate). Statistical significance of effects was evaluated using likelihood ratio tests comparing the full model to a model without the effect being tested.

\section{Results}

\subsection{Experimental oiling}

Prior to oil application, there was no difference in observed surface temperatures between treatment groups for any body part (F-test; $\mathrm{p}>0.05)$. After one oil application, FLIR images demonstrated that the breast and back surface temperatures in the oiled birds were significantly higher than in the control birds (Table 3, Fig. S2). After subsequent oil exposure, FLIR images revealed that breast, back, neck and head temperatures were all significantly higher in the oiled birds than in the control birds (Table 3 ). There was no significant difference in mean daily internal body temperatures $\left(\chi^{2}(2)=4.76, \mathrm{p}=0.09\right)$ or minimum daily body temperatures $\left(\chi^{2}(2)=1.45, \mathrm{p}=0.48\right)$ over the study period between oiled and unoiled birds.

Prior to oil applications, there was no significant effect of treatment alone $\left(\chi^{2}(2)=0.89, \mathrm{p}=0.64\right)$ or interaction between treatment and day $\left(\chi^{2}(1)=0.36, p=0.55\right)$ on observed food consumption (Fig. S4a). Birds in both groups were decreasing food consumption by $4-5 \mathrm{~g} \mathrm{~kg}^{-1} \mathrm{~d}^{-1}$ over the course of the quarantine period. Following the start of oil application, the treatment group became a significant determinant of food consumption (Fig. S4b). Control birds continued to decrease food consumption over time, although at a slower rate, while birds in the oiled group began to increase food consumption. In the post-oiling period, the interaction between experiment day and treatment had a significant effect on food consumption $\left(\chi^{2}(1)=10.426\right.$, $\mathrm{p}=0.0012$ ), with oiled birds eating more food as the experiment progressed.

During Stage 1 (excluding first day of oiling due to abnormally low consumption) oiled birds were observed to eat $10 \%$ less food than control birds. In Stage 2 and Stage 3 days, oiled birds were observed to eat $15 \%$ and $20 \%$, more, respectively, than the control birds (Table S4). The oiled birds were able to maintain their body weight as well as the control birds, with the exception of two individuals that quickly lost weight immediately prior to death (Table S2, Fig. S5).

\subsection{Unoiled model}

Niche Mapper's metabolic rate predictions for unoiled cormorants resting in air were comparable to experimental data from live cormorants (Fig. 1). For cormorants in air, Niche Mapper predicted a lower critical temperature between 10 and $15^{\circ} \mathrm{C}$ and an upper critical temperature between 27 and $31^{\circ} \mathrm{C}$. Below the thermoneutral zone, predicted whole body thermal conductance was between 0.33 and $0.44 \mathrm{~W} /$ ${ }^{\circ} \mathrm{C}$ in the simulated chamber (Table 4). For cormorants resting on the water surface, Niche Mapper metabolic rate predictions were within the range of metabolic rates observed in live cormorants (Fig. 1). Water exposure increased the predicted lower critical temperature to $24^{\circ} \mathrm{C}$ and whole body thermal conductance to $1.15-1.24 \mathrm{~W} /{ }^{\circ} \mathrm{C}$ (Table 4).

Niche Mapper's predicted surface temperatures when modeling unoiled cormorants in the photograph room were within $1.2 \pm 0.3^{\circ} \mathrm{C}$ of the mean ( \pm s.e.) observed temperatures for the beak, $0.3 \pm 0.2^{\circ} \mathrm{C}$ for the head, $2.5 \pm 0.3^{\circ} \mathrm{C}$ for the neck, $0.8 \pm 0.3^{\circ} \mathrm{C}$ for the back, and $1.0 \pm 0.3^{\circ} \mathrm{C}$ for the legs (Fig. 2a; Fig. S3a-f). Niche Mapper predicted higher breast temperatures by $4.2 \pm 0.5^{\circ} \mathrm{C}$ compared to average values from the FLIR images when assuming the photograph room air temperatures. With one exception (breast, day 10), the measured mean surface temperatures for all body parts on all days fell between the surface temperatures predicted by Niche Mapper when using the photograph room air temperatures and those predicted when using the animal room air temperatures (Fig. 2a).

Table 3

Average surface temperature $\left({ }^{\circ} \mathrm{C}\right)$ for different body parts as measured in FLIR images of oiled and unoiled cormorants after different levels of oil exposure. Asterisks indicate that the surface temperature for that body part was significantly different than for the control group.

\begin{tabular}{|c|c|c|c|c|c|c|c|}
\hline \multirow[t]{2}{*}{ Oil applications } & \multirow[t]{2}{*}{ Group } & \multicolumn{6}{|l|}{ Body part } \\
\hline & & Beak & Head & Neck & Breast & Back & Legs \\
\hline \multirow[t]{2}{*}{ Prior to oiling ${ }^{\mathrm{a}}$} & Oil & $29.4 \pm 0.3$ & $29.4 \pm 0.4$ & $25.1 \pm 0.4$ & $20.1 \pm 0.3$ & $26.9 \pm 0.3$ & $24.7 \pm 0.8$ \\
\hline & Control & $29.6 \pm 0.4$ & $29.0 \pm 0.3$ & $25.0 \pm 0.3$ & $20.2 \pm 0.2$ & $26.3 \pm 0.3$ & $25.0 \pm 1.2$ \\
\hline \multirow[t]{2}{*}{ One application ${ }^{\mathrm{b}}$} & Oil & $26.0 \pm 0.3^{*}$ & $26.9 \pm 1.1$ & $22.4 \pm 0.5$ & $16.9 \pm 0.2^{*}$ & $26.3 \pm 0.3^{*}$ & $22.0 \pm 0.8$ \\
\hline & Control & $28.0 \pm 0.3$ & $27.8 \pm 0.3$ & $22.8 \pm 0.3$ & $15.8 \pm 0.4$ & $23.1 \pm 0.2$ & $21.5 \pm 1.1$ \\
\hline \multirow[t]{2}{*}{ Three applications $^{\mathrm{b}}$} & Oil & $25.8 \pm 0.4$ & $30.3 \pm 0.2^{*}$ & $24.6 \pm 0.3^{*}$ & $17.2 \pm 0.4^{*}$ & $27.9 \pm 0.3^{*}$ & $18.4 \pm 0.6$ \\
\hline & Control & $25.9 \pm 0.4$ & $27.9 \pm 0.2$ & $22.6 \pm 0.3$ & $14.4 \pm 0.3$ & $22.4 \pm 0.3$ & $21.0 \pm 1.3$ \\
\hline \multirow[t]{2}{*}{ Five applications ${ }^{\mathrm{b}}$} & Oil & $27.6 \pm 0.4$ & $30.6 \pm 0.4^{*}$ & $25.2 \pm 0.4^{*}$ & $19.0 \pm 0.2^{*}$ & $29.2 \pm 0.4^{*}$ & $19.7 \pm 1.1$ \\
\hline & Control & $27.2 \pm 0.4$ & $28.3 \pm 0.5$ & $23.0 \pm 0.4$ & $15.8 \pm 0.3$ & $22.9 \pm 0.5$ & $21.6 \pm 1.1$ \\
\hline \multirow[t]{2}{*}{ Six applications $\mathrm{s}^{\mathrm{a}}$} & Oil & $30.4 \pm 0.6$ & $31.1 \pm 0.4^{*}$ & $27.0 \pm 0.3^{*}$ & $22.8 \pm 0.3^{*}$ & $30.2 \pm 0.5^{*}$ & $27.1 \pm 0.9^{*}$ \\
\hline & Control & $29.3 \pm 0.4$ & $29.6 \pm 0.2$ & $24.4 \pm 0.3$ & $19.0 \pm 0.3$ & $24.8 \pm 0.4$ & $23.7 \pm 0.4$ \\
\hline
\end{tabular}

\footnotetext{
a Photograph room air temperature was $20^{\circ} \mathrm{C}$.

b Photograph room air temperature was $17^{\circ} \mathrm{C}$.
} 


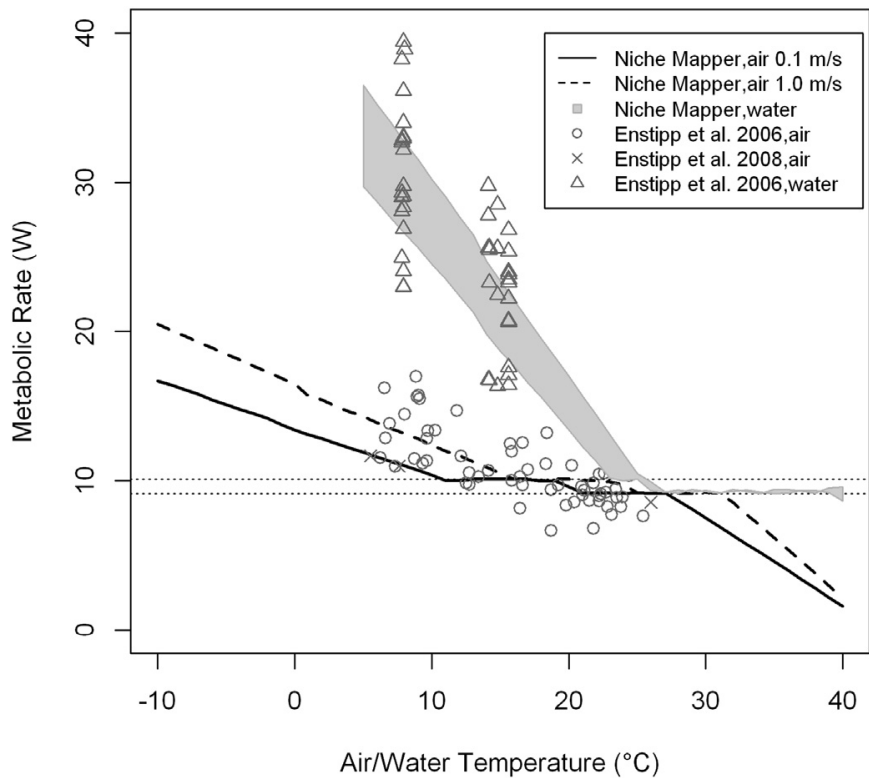

Fig. 1. Niche Mapper (NM) metabolic rate predictions as a function of air and/ or water temperature for a resting, average-sized $(2.1 \mathrm{~kg})$ cormorant using the input values from Table 1 compared to values reported for live cormorants. The shaded gray indicates the range of NM predictions assuming different percentages of the torso submerged in water (50\%-90\%) and air/water velocities from $0.1 \mathrm{~m} / \mathrm{s}$ to $1.0 \mathrm{~m} / \mathrm{s}$. NM thermoregulates until it reaches a metabolic heat production within $5 \%$ of the resting metabolic rate (horizontal dashed lines). Predicted metabolic rates below the target range are unrealistic, but are included to show temperatures at which overheating is predicted to occur.

\subsection{Oiled model}

For the oiled birds, making the changes summarized in Table 2 resulted in surface temperatures predictions within $0.4 \pm 0.1{ }^{\circ} \mathrm{C}$ of the mean observed temperatures for the beak, $1.0 \pm 0.1^{\circ} \mathrm{C}$ for the head, $1.9 \pm 0.1{ }^{\circ} \mathrm{C}$ for the neck, $0.3 \pm 0.2{ }^{\circ} \mathrm{C}$ for the back, and $0.9 \pm 1.2{ }^{\circ} \mathrm{C}$ for the legs (Fig. 2b; Fig. S3g-j). As with the unoiled birds, Niche Mapper predicted higher breast temperatures $\left(4.0 \pm 0.3^{\circ} \mathrm{C}\right)$ when assuming the air temperature of the photograph room for the modeling. Predicted breast surface temperatures were closer to observed surface temperatures when using animal room air temperatures (mean difference $=0.29 \pm 0.4^{\circ} \mathrm{C}$ ).
In the metabolic chamber simulations of oiled cormorants in air, the predicted lower critical temperature increased by $7-12^{\circ} \mathrm{C}$ and the predicted upper critical temperature increased by $3-5{ }^{\circ} \mathrm{C}$ (Table 4 , Fig. S6). Predicted whole body thermal conductance $\left(\mathrm{W} /{ }^{\circ} \mathrm{C}\right)$ below the lower critical temperature of the unoiled model were increased by $32-73 \%$, resulting in $31-76 \%$ increases in metabolic heat production required to maintain body temperatures (Table 4, Fig. S6). In the metabolic chamber simulations of oiled cormorants resting in water, metabolic rates and whole body thermal conductivities increased $13-46 \%$ and $10-35 \%$, respectively, compared to the unoiled model resting in water (Table 4; Figs. S6, S7). As the degree of assumed water penetration increased, the difference between the oil stages decreased as the heat loss to water overwhelms other heat loss to the point where assuming full water penetration resulted in virtually identical predictions for all oiling stages.

\subsection{Predicted food intake}

Predicted daily food requirements were relatively constant throughout the experiment for unoiled birds, indicating little change in predicted thermoregulatory costs (Fig. 3a). For oiled group, Niche Mapper predicted virtually identical food requirements as the control birds up until oil applications began (Fig. 3b). Following oil application, Niche Mapper predicted food requirement increases of $10 \%, 13 \%$, and $15 \%$ for oiled birds compared to the control birds for Stage 1, 2, and 3 oiling, respectively (Table S3). Compared to observed food consumption, predicted food requirements were generally lower than those observed, particularly in the quarantine period.

\section{Discussion}

\subsection{Model development and testing}

Oiled cormorants had significant increases in surface body temperatures after a single exposure to $13 \mathrm{~g}$ of oil and exhibited a cumulative effect over time, relative to unoiled birds due to repeated exposure to sublethal amounts of oil (Table 3). The effects of oil exposure predicted by Niche Mapper are comparable to experimentally induced effects observed here in cormorants and from the literature for multiple species (Table S1). Using food consumption as a proxy for energetic expenditure, oiled cormorants consumed as much as $20 \%$ more food than unoiled cormorants and Niche Mapper predicted a similar trend and magnitude of increased food consumption due to increased thermoregulatory costs of repeated sublethal oil exposure. These findings

Table 4

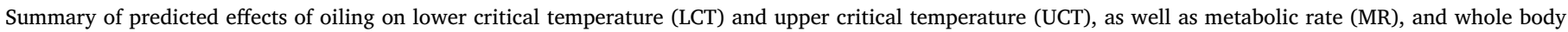

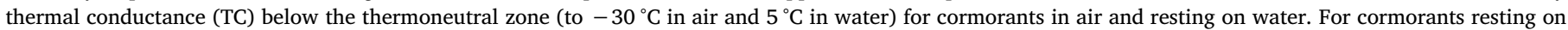
water, modeling assumed that $70 \%$ of the torso was submerged. Two air/water velocities were also assumed: $0.1 \mathrm{~m} / \mathrm{s}$ and $1.0 \mathrm{~m} / \mathrm{s}$.

\begin{tabular}{|c|c|c|c|c|c|c|c|}
\hline & \multirow[t]{2}{*}{ Model } & \multicolumn{3}{|c|}{$0.1 \mathrm{~m} / \mathrm{s}$ velocities } & \multicolumn{3}{|c|}{$1.0 \mathrm{~m} / \mathrm{s}$ velocities } \\
\hline & & LCT/UCT $\left({ }^{\circ} \mathrm{C}\right)$ & MR & TC & LCT/UCT $\left({ }^{\circ} \mathrm{C}\right)$ & MR & TC \\
\hline \multirow[t]{4}{*}{ Air } & Unoiled & $10 / 27$ & $10.4-23.8$ & 0.33 & $15 / 31$ & $10.5-30.4$ & 0.44 \\
\hline & Stage 1 & $17 / 30$ & $13.3-31.3$ & 0.44 & $22 / 33$ & $13.8-40.5$ & 0.58 \\
\hline & Stage 2 & $20 / 32$ & $15.6-36.8$ & 0.52 & $25 / 36$ & $16.6-49.6$ & 0.69 \\
\hline & Stage 3 & $22 / 32$ & $17.0-40.2$ & 0.57 & $26 / 36$ & $18.2-54.3$ & 0.76 \\
\hline \multirow[t]{8}{*}{ Water } & Unoiled & $24 / 39$ & $10.2-32.0$ & 1.15 & $24 />40$ & $10.8-34.4$ & 1.24 \\
\hline & Stage $1^{\mathrm{a}}$ & $25 />40$ & $11.8-35.8$ & 1.26 & $25 />40$ & $12.7-38.9$ & 1.38 \\
\hline & Stage $2^{\mathrm{a}}$ & $25 />40$ & $12.3-36.5$ & 1.28 & $26 />40$ & $13.6-40.4$ & 1.41 \\
\hline & Stage $3^{\mathrm{a}}$ & $26 />40$ & $13.8-51.0$ & 1.38 & $27 />40$ & $15.1-44.1$ & 1.53 \\
\hline & Stage $1^{b}$ & $26 />40$ & $13.8-40.2$ & 1.39 & $27 />40$ & $14.7-43.3$ & 1.51 \\
\hline & Stage $2^{\mathrm{b}}$ & $26 />40$ & $14.0-40.4$ & 1.39 & $27 />40$ & $15.4-44.5$ & 1.53 \\
\hline & Stage $3^{\mathrm{b}}$ & $27 />40$ & $15.0-42.8$ & 1.46 & $27 />40$ & $16.4-47$ & 1.61 \\
\hline & All stages ${ }^{c}$ & $28 />40$ & $16.6-47.0$ & $1.57-1.58$ & $28 />40$ & $19.0-50.5$ & $1.71-1.72$ \\
\hline
\end{tabular}

\footnotetext{
a Assuming oil exposure does not cause additional water penetration.

b Assuming oil exposure reduces insulating layer to $1 \mathrm{~mm}$.

c Assuming oil exposure allows water to penetrate all the way to the skin.
} 

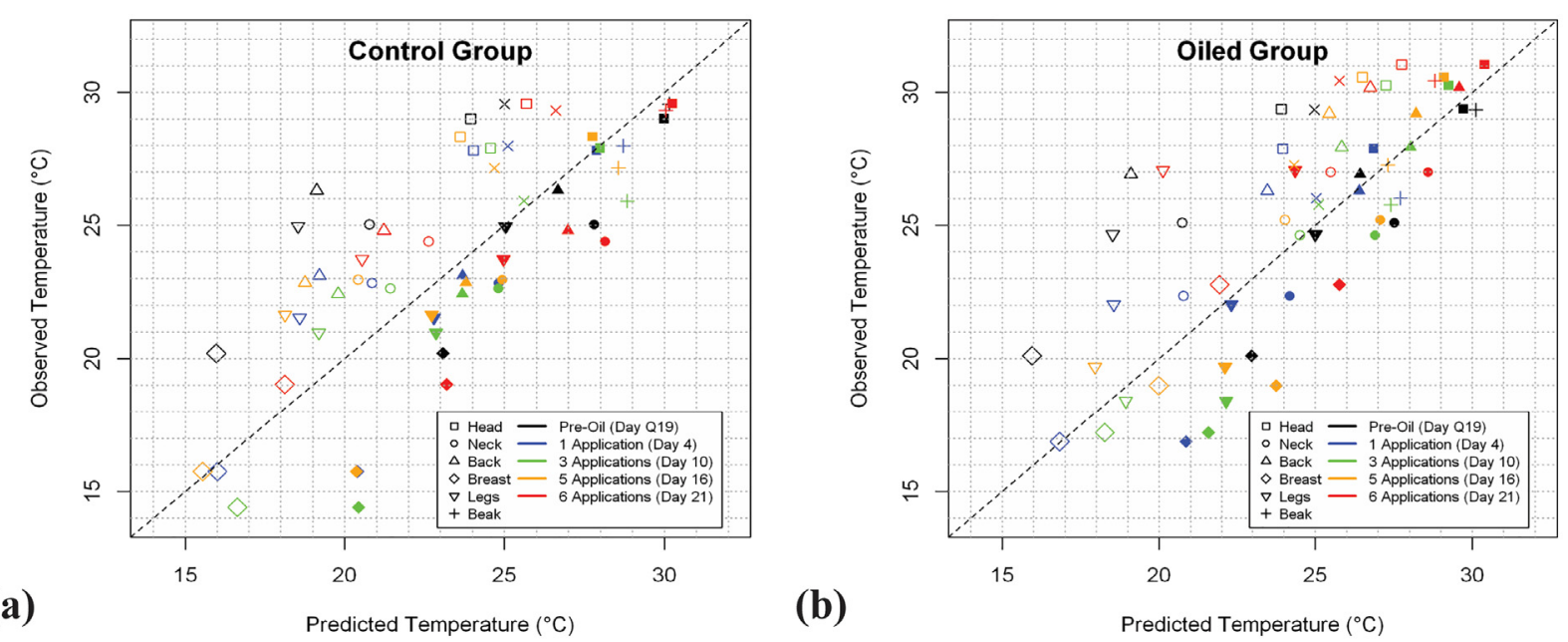

Fig. 2. Surface temperatures predicted by Niche Mapper (NM) compared to mean surface temperatures measured by FLIR imagery on control (a) and oiled (b) live cormorants. Filled ("+" for the beak) symbols are temperature predictions assuming air temperatures of the photograph room. Open ("X" for the beak) symbols represent predictions assuming air temperatures of the animal room prior to the photographs being taken. Points above and below the dashed 1:1 line indicate NM under- and overpredicting surface temperatures, respectively. Note how the 1:1 line lies between the two sets of predictions.
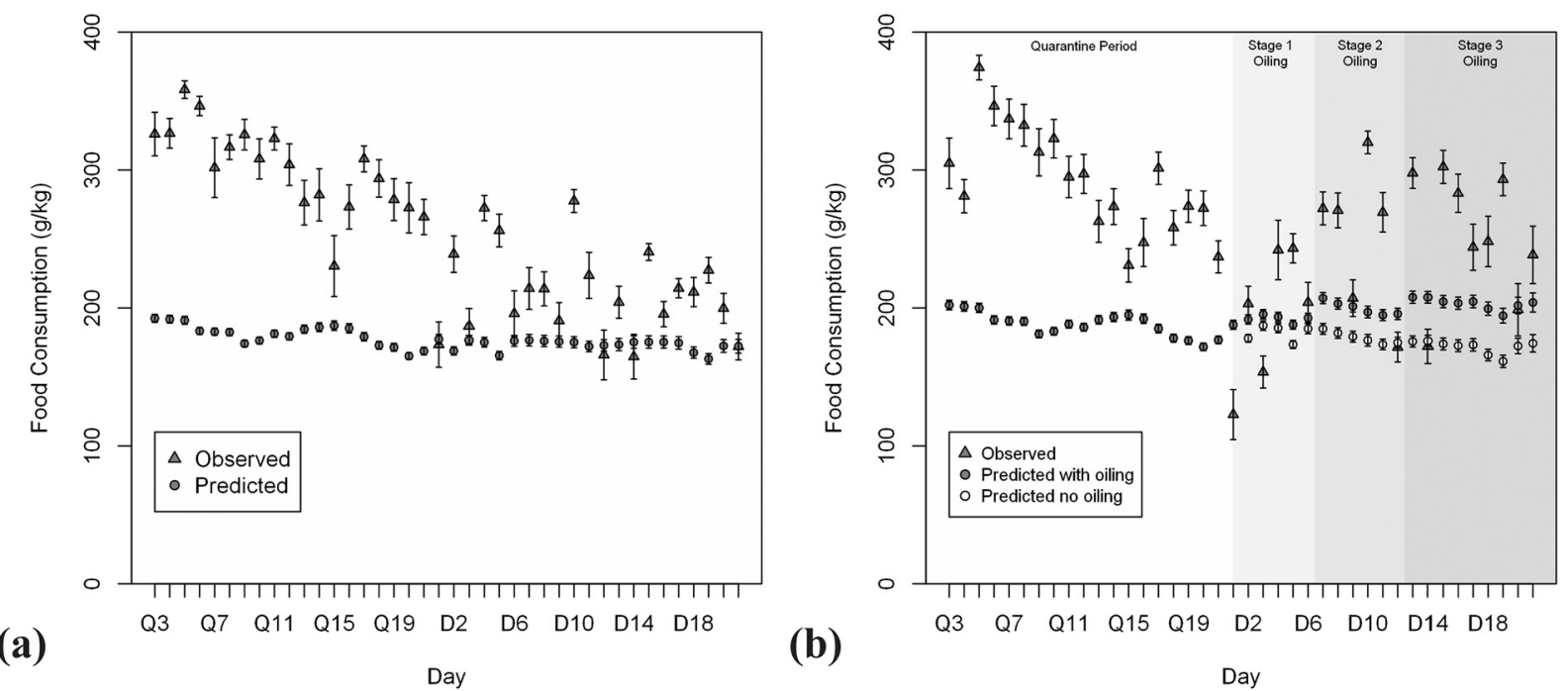

Fig. 3. Niche Mapper predictions for mean daily food consumption per unit body mass ( \pm s.e.) compared to observed consumption for the control (a) and oiled (b) cormorant groups. For the oiled group, also shown for comparison is the predicted food consumption of those individuals if no oiling was modeled. Intragroup variation predicted by Niche Mapper is solely due to differences in mass-specific energetic demands; body mass was the only model input that changed between individual simulations.

provide support for both the cumulative thermoregulatory effects of repeated sublethal oil exposure on cormorants and for Niche Mapper's ability to predict the thermoregulatory consequences of oil exposure in birds.

The ability to accurately model thermoregulatory effects of repeated sublethal oil exposure is predicated on accurately modeling how oiling affects body surface temperatures because heat fluxes with the environment depend on animal surface temperatures. Overall, Niche Mapper's surface temperature predictions for unoiled cormorants agreed with observed surface temperatures in unoiled cormorants. Importantly, the observations were made in temperatures within the cormorant's expected thermoneutral range, and Niche Mapper calculated similar surface temperatures while assuming an experimentallyreported resting metabolic rate and the same body temperature as the live cormorants.

For the oiled bird models, the modifications to plumage inputs for the baseline (unoiled) model that allowed for the calculated surface temperatures to match the measured surface temperatures of oiled birds were logical and based on observed effects to the plumage (Cunningham et al., 2017), thus supporting the model's ability to accurately model heat flow processes in cormorants. For example, in the live bird experiment oil was applied only to the back and breast, and thus oil would need to be spread to the neck and head via preening over time. In the modifications for Stage 1 oiling, modeling the immediate introduction of oil to the head and neck resulted in surface temperatures being too high. However, oil introduction to the head and neck was required for Stage 2 and 3 models in order to match observed surface temperatures on these body parts.

While Niche Mapper accurately predicted surface temperatures for most body areas overall, the breast area varied dependent on the underlying ambient temperatures modeled. Predicted breast surface temperatures were more accurate when the model assumed temperatures associated with the animal holding room than when assuming the temperature of the photograph room (Fig. 2). A likely explanation for this difference is the thicker plumage $(12 \mathrm{~mm})$ on the breast that prevents the surface from reaching a steady state as quickly as other body 
parts with thinner $(<4 \mathrm{~mm})$, or no, plumage. After only a few minutes in the photograph room, breast surface temperatures may still be more reflective of the birds in the animal room temperatures. Indeed, the observed breast surface temperatures were closer to the surface temperatures predicted by Niche Mapper when assuming the animal room air temperature.

Niche Mapper's metabolic heat production predictions for the unoiled cormorant model in a simulated metabolic chamber were similar to measurements made on live, unoiled cormorants in air and in water (Fig. 1). Metabolic chamber data do not exist for oiled cormorants for a similar comparison for our oiled cormorant models. However, changes in metabolic heat production and whole body thermal conductance in response to oiling reported for other species (Table S1) are useful points of comparison to evaluate Niche Mapper's predictions as we discuss below.

Lower levels of oil exposure $(<20 \mathrm{~g}$ or "light" in Table S1) have been found to increase whole body thermal conductance in live birds in air by $0-84 \%$. Niche Mapper predicted thermal conductance would increase $33 \%$ in cormorants in response to Stage 1 oiling, within the reported range for other species. Prior studies of oiled birds exposed to air found that heat production increased by $8-20 \%$ following exposure to $\sim 12 \mathrm{~mL}$ of crude oil (Table S1). Here, Stage 1 oiling represents exposure to a similar amount of crude oil $(13 \mathrm{~g})$, and the model predicted a $31-33 \%$ increase in metabolic heat production in cormorants.

Moderate oil exposure (20-50 g or "moderate" in Table S1) has been found to increase thermal conductance by $45-113 \%$ in live birds in air. In our study, Stage 2 oiling represents exposure to a total of $39 \mathrm{~g}$ of crude oil, and Niche Mapper predicted whole body thermal conductance would increase by $58 \%$, within the reported range for other species. High levels of oil exposure ( $>50 \mathrm{~g}$ or "heavy" in Table S1) has been found to increase thermal conductance by $74-143 \%$ in live birds in air. Here, Stage 3 oiling represents exposure to a total of 65-91 g of crude oil, and Niche Mapper predicted whole body thermal conductance would increase by $73 \%$ in response to this exposure. McEwan and Koelink (1973) found that moderate and heavy oiling increased the lower critical temperature for mallards (Anas platyrhynchos) and scaups (Aythya sp.) by $13^{\circ} \mathrm{C}$. At this oiling level, Niche Mapper provided a similar response, predicting that lower critical temperatures would increase $10-12{ }^{\circ} \mathrm{C}$ in response to Stage 2 or 3 oiling.

We note that the studies in Table S1 applied oil in a single dose, while our oiled models were based on repeated applications to simulate chronic exposure. Thus, while Stage 3 oiling reflects cumulative application of 65-91 $\mathrm{g}$ of oil, some of the oil had likely been removed by preening or while swimming by the time the FLIR images used to calibrate the model were taken. This could contribute - along with intrinsic differences between plumage structure between species (sensu Jenssen, 1994)- to Niche Mapper's predictions for responses to moderate or heavy exposure being on the lower end of what has been reported in the literature. Given that we are modeling repeated sublethal exposure to oil, an observed scenario for many birds (see Bursian et al., 2017), these results may reflect a more realistic situation with respect to thermoregulatory impacts of real-world oil exposure.

Predicted responses in metabolic heat production and whole body thermal conductance for oiled cormorants exposed to water are generally lower than what has been reported for other species (Tables 4, S1). However, cormorant plumage is partially wettable, and it is reasonable to expect a bird whose plumage naturally allows some water penetration prior to oil exposure to display less response after oiling than a bird whose plumage better resists water penetration. Indeed, unoiled cormorants increase metabolic rate $165-219 \%$ when resting in water compared to resting in air, while unoiled mallards and eiders only increase their metabolic rates 4-56\% (Richman and Lovvorn, 2011). This indicates that unoiled cormorants experience much of the increased heat production documented in oiled mallards and eiders exposed to water simply as a result of its partially-wettable plumage, leaving less opportunity for oil exposure to cause additional heat loss.
These findings indicate the importance and capability of Niche Mapper for modeling for plumage specific characteristics of avian species. Given this capability, empirical measurements of metabolic rates and buoyancy changes of oiled cormorants in water would be helpful to refine Niche Mapper predictions at various oil exposure levels.

\subsection{Feeding trial experiment}

Overall, oiled cormorants consumed as much as $20 \%$ more food than unoiled cormorants and Niche Mapper predicted up to $18 \%$ increased food consumption due to increased thermoregulatory costs of repeated sublethal oiling. While the overall direction and magnitude of change in predicted increases in food consumption were similar to observed changes, Niche Mapper did tend to underestimate absolute food consumption, particularly early in the study. Live birds lost weight (mean: $385 \pm 23 \mathrm{~g}$; no difference between control and oiled groups) between capture and surgery, and then gained weight, mainly in the quarantine period (Fig. S5). However, Niche Mapper's food requirements are calculated to exactly meet the energetic demands for maintaining body mass, activity, and thermoregulation and do not account for growth. As weight gains slowed toward the end of the experiment, the observed food consumption converged with the food requirements predicted by Niche Mapper (Fig. 3a).

During Stage 1 oiling days, Niche Mapper predicted that oiled birds would require $10 \%$ greater food consumption than control birds. However, the oiled birds were observed to eat less food than control birds, despite having higher body surface temperatures, and thus presumably requiring greater metabolic heat production. This overestimation could be explained by the first few days following oil application being a period of reduced food consumption while adjusting to the physical effects of being oiled.

During Stage 2 and 3 oiling days, oiled birds consumed more than the control birds, consistent with Niche Mapper's predicted increased thermoregulatory costs. Niche Mapper's underestimation (predicted $15-18 \%$ increase vs. observed $20 \%$ increase) of Stage 3 food consumption could be explained by factors other than increased thermoregulatory demands influencing food consumption at this exposure level. Anecdotal evidence suggests that oiled birds may have increased activity costs due to additional preening (Cunningham et al., 2017). Also, Harr et al. (2017a, 2017b) observed increased edema, and loss of blood in gastrointestinal tracts and feces in some oiled birds, suggesting that oil ingestion could interfere with physiological factors such digestive efficiency or nutrient utilization.

The fact that observed food consumption did not solely reflect daily energy expenditure for maintenance, does not affect the main results of this study. The relevant comparison is how the predicted difference in food consumption between the oiled and unoiled birds compared to the observed difference between the groups. Prior to oiling, the groups had similar food consumption; following oiling, the oiled group was observed to increase food consumption compared to the control group. This difference must be attributed to the oiling because the birds were otherwise treated identically, and the increases are consistent with Niche Mapper's predictions of increased thermoregulatory requirements due to reduced plumage insulation.

Niche Mapper accurately predicted heat production by unoiled cormorants over a wide temperature range as evidenced by the metabolic chamber simulations (Fig. 1). For the oiled models, Niche Mapper produced similar surface temperatures as observed in live birds (Fig. 2) when logical modifications based on qualitative observations were made to the plumage layer inputs. We are confident in these predictions because we are explicitly modeling the heat transfer processes determining surface temperatures rather than relying on correlations between air and surface temperatures. That being said, empirical measures of changes in some modeled parameters such physical changes to plumage, depth of water penetration, and surface temperature measures at a wider range of ambient temperatures may help inform the 
relationship of various physical and physiological changes and specific heat transfer processes.

The above suggestions would help in understanding the relative contributions of various physical and physiological processes to the overall impacts of sublethal exposure to oil on avian or any other insulated endotherm thermoregulation. That said, an advantage of Niche Mapper is this information is not necessarily required to measure overall thermoregulatory impacts. For example, when extending this work to other species, it ultimately does not matter whether the model captures the precise characteristics of changes (e.g., plumage structural changes) as long as the resulting change to plumage layer insulation is reasonable. One way to do this is to simply modify plumage inputs until a desired level (or range) of increased whole-body thermal conductivity is achieved in the model, based on the range reported for other species (e.g., Table S1).

\subsection{Implications}

This work illustrates the cumulative thermoregulatory impacts of repeated sublethal exposure to oil in cormorants and how bioenergetics models can be used to provide important insight into thermoregulatory costs of oil exposure. As far as we are aware this is the first time that a bioenergetics model has been tested with live animal experiments for this purpose. The ability to model the effects of oil exposure are valuable because such information would be difficult and resource-intensive to obtain from direct measurements of wild animals. Exposure to wind and a wider range of temperatures experienced in natural habitats, including the generally cooler temperatures experienced at higher-latitude breeding grounds would be expected to increase thermoregulatory costs compared to what was reported here, and absence of ad libitum food may make compensation more difficult. Such information can provide valuable insight into how both large and chronic oil spills are affecting wildlife by quantifying the extent to which thermoregulatory costs are diverting resources away from other important life processes like reproduction and building energy stores for migration. We used cormorants as a model organism, but the approach can be generalized to any species for which the basic morphological and physiological information needed by Niche Mapper is known.

\section{Acknowledgments}

The captive animal study was funded by the U.S. Fish and Wildlife Service as part of the Deepwater Horizon Natural Resource Damage Assessment. Animal capture, care, and use were approved by IACUC and NWRC Attending Veterinarian under protocol QA-2326 and Federal \#MB019065-3, Mississippi and Alabama (\#8017) scientific collection permits. The National Wildlife Research Center provided funding for the modeling. Special thanks to Alexander Crain, Lanna Durst, Paul Fioranelli, Raleigh Middleton, and Paul Burr for their technical assistance with animal care and sampling on this project. We thank Scott Willard for use of the FLIR camera. We thank Ben Zuckerberg for statistical advice and Bill Karasov for helpful comments on previous drafts of this manuscript. Constructive feedback from three anonymous reviewers also improved this work.

\section{Appendix A. Supplementary data}

Supplementary data to this article can be found online at https:// doi.org/10.1016/j.marpolbul.2018.07.003.

\section{References}

Bates, D., Maechler, M., Bolker, B., Walker, S., 2015. Fitting linear mixed-effects models using lme4. J. Stat. Softw. 67, 1-48.

Brugger, K.E., 1993. Digestibility of three fish species by double-crested cormorants.
Condor 95, 25-32.

Bursian, S.J., et al., 2017. Overview of avian toxicity studies for the Deepwater Horizon Natural Resource Damage Assessment. Ecotoxicol. Environ. Saf. 142, 1-7.

Cho, B.T. (Ed.), 1969. Advanced Heat Transfer. U Illinois Press, Urbana, IL (459 pp.).

Cunningham, F., et al., 2017. Development of methods for avian oil toxicity studies using the double crested cormorant (Phalacrocorax auritus). Ecotoxicol. Environ. Saf. 141, 199-208.

Dorr, B.S., et al., 2015. DWH avian toxicity phase 2: double-crested cormorant (Phalacrocorax auritus) external oiling scoping study (M23). In: Final Report to USFWS, Natural Resource Damage Assessment, (47 pp.).

Elam, S.K., Tokura, I., Saito, K., Altenkirch, R.A., 1989. Thermal conductivity of crude oils. Exp. Thermal Fluid Sci. 2, 1-6.

Enstipp, M.R., Grémillet, D., Jones, D.R., 2006. The effects of depth, temperature and food ingestion on the foraging energetics of a diving endotherm, the double-crested cormorant (Phalacrocorax auritis). J. Exp. Biol. 209, 845-859.

Enstipp, M.R., Grémillet, D., Jones, D.R., 2008. Heat increment of feeding in doublecrested cormorants (Phalacrocorax auritus) and its potential for thermal substitution. J. Exp. Biol. 211, 49-57.

Fitzpatrick, M.J., Mathewson, P.D., Porter, W.P., 2015. Validation of a mechanistic model for non-invasive study of ecological energetics in an endangered wading bird with counter-current heat exchange in its legs. PLoS One 10, e0136677.

Fort, J., Porter, W.P., Grémillet, D., 2009. Thermodynamic modeling predicts energetic bottleneck for seabirds wintering in the northwest Atlantic. J. Exp. Biol. 212, 2483-2490.

Fort, J., Porter, W.P., Grémillet, D., 2011. Energetic modeling: a comparison of the different approaches uses in seabirds. Comp. Biochem. Physiol. A Mol. Integr. Physiol. 158, 358-365.

Fraser, G.S., Racine, V., 2016. An evaluation of oil spill responses for offshore oil pro duction projects in Newfoundland and Labrado, Canada: implications for seabird conservation. Mar. Pollut. Bull. 107, 36-46.

Fuentes, M., Porter, W.P., 2013. A new approach to model soil temperature: using mi croclimate models to predict the impacts of climate change on sea turtles. Ecol. Model. 251, 150-157.

Göktepe, Ö., Hundt, P., Porter, W., Pereira, D., 2012. Comparing bioenergetics models of double-crested cormorant (Phalacrocorax auritus) fish consumption. Waterbirds 35, 91-102.

Goldstein, D.L., 1988. Estimates of daily energy expenditure in birds: the time-energy budget as an integrator of laboratory and field studies. Am. Zool. 28, 829-844.

Grémillet, D., Tuschy, I., Kierspel, M., 1998. Body temperature and insulation in diving Great Cormorants and European Shags. Funct. Ecol. 12, 386-394.

Grémillet, D., Chauvin, C., Wilson, R.P., Le Maho, Y., Wanless, S., 2005. Unusual feather structure allows partial plumage wettability in diving great cormorants Phalacrocorax carbo. J. Avian Biol. 36, 57-63.

Harr, K.E., et al., 2017a. Weathered MC252 crude oil-induced anemia and abnormal erythroid morphology in double-crested cormorants (Phalacrocorax auritus) with light microscopic and ultrastructural description of Heinz bodies. Ecotoxicol. Environ. Saf. 146, 29-39.

Harr, K.E., et al., 2017b. Comparison of organ weights and histopathology between double-crested cormorants (Phalacrocorax auritus) dosed orally or externally with artificially weathered Mississippi Canyon 252 crude oil. Ecotoxicol. Environ. Saf. 146, 52-61.

Henkel, L.A., Nevins, H., Martin, M., Sugarman, S., Harvey, J.T., Ziccardi, M.H., 2014 Chronic oiling of marine birds in California by natural petroleum seeps, shipwrecks, and other sources. Mar. Pollut. Bull. 79, 155-166.

Jenssen, B.M., 1994. Effects of oil pollution, chemically treated oil, and cleaning on the thermal balance of birds. Environ. Pollut. 86, 207-215.

Mahoney, S.A., 1984. Plumage wettability of aquatic birds. Auk 101, 181-185.

Martin, R.W., Carter, E.P., Flick Jr.G.J., Davis, L.M. (Eds.), 2000. Marine and Freshwater Products Handbook. Technomic Publishing Company, Lancaster PA (963 pp.).

Mathewson, P.D., Porter, W.P., 2013. Simulating polar bear energetics during a seasonal fast using a mechanistic model. PLoS One 8, e72863.

McEwan, E.H., Koelink, A.F.C., 1973. The heat production of oiled mallards and scaup. Can. J. Zool. 51, 27-31.

O'Hara, P.D., Morandin, L.A., 2010. Effects of sheens associated with offshore oil and gas development on the feather microstructure of pelagic seabirds. Mar. Pollut. Bull. 60, 672-678.

Oka, N., Okuyama, M., 2000. Nutritional status of dead oiled Rhinoceros Auklets (Ceronhinca monocerata) in the Southern Japan Sea. Mar. Pollut. Bull. 40, 340-347.

Porter, W.P., Mitchell, J.W., 2006. Method and System for Calculating the SpatialTemporal Effects of Climate and Other Environmental Conditions on Animals. http:// www.warf.org/technologies.jsp?ipnumber $=$ P01251US

R Core Team, 2017. R: A Language and Environment for Statistical Computing. R Foundation for Statistical Computing, Vienna, Austria. https://www.R-project.org/.

Richman, S.E., Lovvorn, J.R., 2011. Effects of air and water temperatures on resting metabolism of auklets and other diving birds. Physiol. Biochem. Zool. 84, 316-332.

Scherr, H., 2009. Breeding Dispersal, Migration, and Winter Movements of the Eastern Interior Population of Double-crested Cormorants. M.Sc. Thesis. Trent University, Peterborough, Ontario, Canada (102 pp.).

United States Department of Agriculture, 2016. USDA Food Composition Database for Standard Reference. Release 28. Available at: https://ndb.nal.usda.gov/, Accessed date: May 2016.

Votier, S.C., et al., 2005. Oil pollution and climate have wide-scale impacts on seabird demographics. Ecol. Lett. 8, 1157-1164.

Wiese, F.K., Robertson, G.J., 2004. Assessing seabird mortality from chronic oil discharges at sea. J. Wildl. Manag. 68, 627-638.

Wiese, F.K., Ryan, P., 2003. The extent of chronic marine oil pollution in southeastern Newfoundland waters assessed through beach bird surveys 1984-1999. Mar. Pollut. Bull. 46, 1090-1101. 